EPiC Series in Engineering
Volume 3, 2018, Pages 408-418
HIC 2018. 13th International
Conference on Hydroinformatics

\title{
Multispectral Approach Assessment for Detection of Losses in Water Transmission Systems by Airborne Remote Sensing
}

\author{
Christian Chatelard ${ }^{1}$, Jean-Claude Krapez ${ }^{1}$, Philippe Barillot ${ }^{1}$, Philippe \\ Déliot $^{2}$, Yves-Michel Frédéric ${ }^{1}$, Jean Pierro ${ }^{1}$, Jean-François Nouvel ${ }^{1}$, Franck \\ Hélias $^{1}$, Yolande Louvet ${ }^{1}$, Isabelle Legoff ${ }^{3}$ and Guillaume Serra ${ }^{3}$ \\ ${ }^{1}$ ONERA The French Aerospace Lab, 13300 Salon de Provence, France \\ ${ }^{2}$ ONERA The French Aerospace Lab, 33000 Toulouse, France \\ ${ }^{3}$ SCP, Le Tholonet 13182 Aix-en-Provence, France \\ christian.chatelard@onera.fr
}

\begin{abstract}
Water losses have a high environmental impact in terms of natural resources depletion (water, energy, ecosystems). This work aims at developing an airborne water leak detection surveillance service to provide water utilities with adequate information on leaks in water transportation mains outside urban areas. As a first step, a series of measurement campaigns were performed with hyperspectral cameras and a thermal infrared camera for selecting the most appropriate wavelengths and combinations thereof for revealing at best high moisture areas and artificial leaks. Further measurements will be performed with thereby optimized instrumentation onboard a plane and a UAV in an operational environment.
\end{abstract}

\section{Introduction}

Detection of water leaks in transmission systems for water supply, irrigation, and hydropower plays a key role in water management efforts to mitigate natural resources depletion, decrease the related energy consumption required in the process and help utilities in providing services more costeffectively. Improved leak management could boost the network efficiency obtaining significant environmental benefits since, in some places of Europe, as much as $50 \%$ of water resources are being lost before they reach the tap. Leaks in large-diameter pipelines for water transportation are estimated to make up less than $5 \%$ of the total number of leaks, yet they can account for more than $50 \%$ of the total water loss. To date, water leakage detection has been carried out by a number of ground techniques that typically involve measurement of pressure differences between two valves, acoustic sounding and ground penetrating radar. However, contrarily to leak detection in distribution pipes, the 
use of ground methods is difficult and often inadequate for water transmission mains, especially out of urban area. There is a strong need for developing surveillance methods that will offer an efficient and cost-effective way for pipeline monitoring. In addition to underground transportation means, the problem of water leaks also affects open canals in which case they are presented as seepage in the embankments.

In the close vicinity of a water leak, thanks to the joint effect of water diffusion and capillarity, soil moisture increases up to the surface. On the other side, in case where vegetation is present, a higher amount of water in the root zone has direct consequences on the water content in the vegetation canopy and the plant vigor. All together, it is expected that underground leaks will induce an enhancement of water presence at the upper surface of the soil/vegetation complex.

Remote sensing provides powerful means for large-scale characterization and monitoring of soil moisture close to the land surface. Depending on the considered spectral band, optical remote sensing relies on variations in optical reflectance or variations in thermal emission. Optical reflectance changes with the water content for both soil and vegetation (e.g. wet soils look darker). In the first case, the optical signal provides information on the moisture in the upper layer of the soil, whereas in the second case, the optical signal gives indication on the leaf water content and thereby, indirectly, on the root-zone soil moisture. On the other side, thermal emission depends on surface emissivity and surface temperature (for natural surfaces, the emissivity is generally very high, close to 1). Surface temperature is conditioned by heat exchanges with the atmosphere as well as by the thermal properties of the underlying material. Water present in soil or vegetation generates latent heat losses through evaporation, resp. transpiration. In the same time, since it induces an increase of the thermal effusivity of soil and the heat capacity of vegetation, it dampens the amplitude of the temperature variations caused by the variations of the atmosphere forcing (e.g. day-night variations of the radiative flux). It is thus expected that, during a sunny day, moist sites should show a lower radiance temperature as compared to drier sites, whereas after sunset and before dawn one should observe the opposite [1]. Based on this interpretation, a large number of remote sensing experiments involving thermal infrared (TIR) sensors have been conducted for assessing the moisture state at the Earth's surface or the evaporation rate over vegetated lands.

Airborne TIR has been considered for water leaks and seepage detection along aqueducts, canals, and dikes for more than thirty years [2-9]. In some instances, TIR was considered alone [2, 3, 7] however the detection accuracy was quite low (numerous false positives). Misinterpretations were commonly caused by dense natural vegetation, shadows, farm canals or drainage ditches adjacent to the main canal, small holding ponds or low depression areas of natural drainage. To reduce misinterpretations, TIR was combined with images obtained from visible and NIR cameras [6], from multispectral or hyperspectral cameras [4, 8, 9], from satellite imagery like Landsat TM [5] or Google Earth [8]. The additional visible-to-SWIR spectral bands were used as standalone information or they have been fused for providing various indicators like well-known vegetation indices or moisture indices (NDVI, MSAVI, CRI, SRWI, WBI, NIRRR, etc...) [9]. Images of the vegetation index NDVI could help differentiating the tree and shadow from nearby seepage areas whereas the thermal image alone could not [6].

A synergetic use of TIR and VIS-NIR data like in the Triangle Method may yield more robust water leak detection along water pipes and aqueducts. This approach actually originates from satellite remote sensing. It consists in combining the apparent temperature and a vegetation index like NDVI. When plotting the temperature and the NDVI for all pixels over an area presenting a broad diversity both in cover fraction and in humidity, a scatterplot with a roughly triangular shape is obtained, whence the name: the Triangle Method [10-22]. Note that the vertex of the triangle is often truncated, giving a trapezoidal shape. A water index is then assigned to each point from its relative position with respect to the "wet" edge and the "dry" edge of the triangle/trapezoid [10-14]. More involved approaches consist in using a SVAT model (Soil Vegetation Atmosphere Transfer) in combination with the triangular scatterplot $[11,13,15]$. Recent works considered a supplementary parameter or 
index (albedo [16-18] or CAI-Cellulose Absorption Index [17-18]) in order to remove ambiguities appearing when both soil and vegetation experience large reflectance variations. Most of the time, the Triangle/trapezoid method has been applied to satellite images, hence providing soil moisture maps at low resolution (100-500m) [12-14]. Applications to airborne remote sensing data for getting information on moisture at a higher resolution (1-5m) are less common [15, 17-22]. They actually reveal higher difficulties, one of them being the surface heterogeneity exacerbated by the higher resolution sensors; as a consequence, it imposes a higher demand on the accuracy of the image registration process.

One of the objectives of present work is to evaluate the applicability of the temperature/Vegetation Index (VI) space (i.e. the triangle/trapezoid method) in a water leak detection method based on airborne data. It has been compared to other spectral indices built upon signals in VNIR $(0.5-1 \mu \mathrm{m})$ and SWIR $(1-2.6 \mu \mathrm{m})$ spectral bands. Among them are WISOIL [23], NSMI [24], NINSOL and NINSON $[25,26]$ which have been proposed for sensing soil moisture. We also considered WBI [27, 28], NDWI [28-30] and SRWI [28] which have been suggested to map the vegetation water content. CAI (Cellulose Absorption Index), which is an index suitable for quantifying the fraction of senescent vegetation [31], is expected to provide an indication on water leaks as well. More recently, a triangle/trapezoid method has been proposed where temperature is replaced by a spectral index obtained from a single optical reflectance measurement, namely at $1.6 \mu \mathrm{m}$ or at $2.2 \mu \mathrm{m}$ [32].

A comparison will be made of the results obtained by applying the former methods on a series of natural wet areas and on artificial leaks. They will help upon selecting the most appropriate wavelengths for an optimized multiwavelength system aimed to airplane or UAV remote sensing detection of water leaks.

\section{Methods}

Airborne measurements were conducted over several areas belonging to the water network infrastructure provided by SCP (Société du Canal de Provence - France) with ONERA's aerial platform (BUSARD) instrumented with two hyperspectral VNIR and SWIR cameras (Hyspex) and a

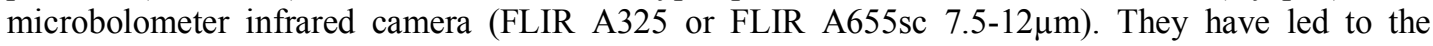
development of a database from which the relevant physical parameters (soil/vegetation brightness temperature, spectral reflectance...) have been extracted.

A first area, Esparron, was selected where SCP operating center has been alerted about a high moisture area not far from the pipe location. Three other sites have also been selected where artificial water leaks were introduced (Le Tholonet, Vauvenargues and Rians): new secondary pipes have been connected to the existing main pipe and buried at a depth of about $1 \mathrm{~m}$; the connection with the existing pipe was equipped with a valve, a flow meter, a recorder and a pressure regulator; calibrated holes have been drilled in the added pipes to generate leakages. In the site of Le Tholonet, a reference zone with a similar dig-work but without any buried pipe was added in order to be able to discriminate between dig-work effects and leak effects. Soil moisture in the $5 \mathrm{~cm}$ upper layer was measured during the flights with a portable FDR probe.

Three campaigns were performed in February, April and July 2017; in this paper we will discuss the results obtained in the first two periods.

The hyperspectral images were orthorectified based on DEMs and GPS+IMU data (IMAR itrace F200). The calibrated radiance images were then corrected from atmosphere attenuation and translated into reflectance images. On the other side, the image sequences provided by the focal plane TIR camera were processed with the Correlator3D software (Simactive) to yield ortho-images and then ortho-mosaics. The coregistration of the meta-images originating from the different cameras 
(VNIR, SWIR, TIR) was performed by GeFolki software that has been recently developed at ONERA for the specific application of coregistration of heterogeneous images [33].

The water indexes listed in $\S 1$ could then be computed by combining different wavelength images. On the other hand, the empirical Triangle/Trapezoid method according to [12] was implemented by using either NDVI or OSAVI for the vegetation index. The latter index is expected to be better immune to the spectral variations of bare soil and hence better correlated to the cover fraction [34].

\section{Results}

The first three figures describe the results obtained over the Esparron area by applying the T-VI Triangle/trapezoid method while using OSAVI as vegetation index (Fig. 1). Since in February the vegetation is absent, senescent or still dormant, the OSAVI map presents quite low values, except over one field at left and over the trees. Interestingly, the thermal infrared image (Fig. 2) presents a triangular dark area in the top-right part which roughly corresponds to a couple of fields where standing water had been detected from time to time over the past years. The two-dimensional distribution of the normalized brightness temperature and vegetation index (OSAVI) is in Fig. 3. The cold/wet edge (blue) and the warm/dry edge (red) have been positioned so that the trapezoid figure contains essentially all the scatter, except maybe a few outliers. The relative distance of each dot to the dry edge defines the so-called water index (WI) which is reported in Fig. 4. WI ranges from 0 to 1. A high value of WI, which is reported in blue color in the image, means that soil moisture is at the highest for the considered VI level. One can notice that the triangular area in Fig. 2 showing low temperature is related to a high WI. A close-up is reported in Fig. 5-left where we added the water pipe and two areas over which the average signal and the standard deviation will be computed; this will provide a contrast to noise ratio $(\mathrm{C} / \mathrm{N})$ to be compared with the other spectral methods.



Figure 1: "Esparron" test site : map of the Vegetation Index OSAVI.



Figure 2: "Esparron" test site : mosaic of Thermal Infrared (TIR) images (dark/clear pixels correspond to low/high brightness temperature). 


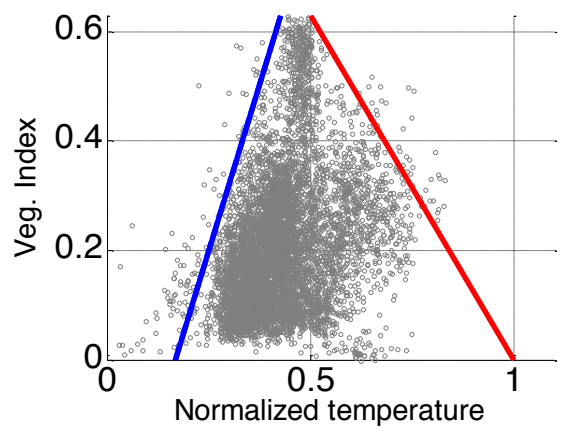

Figure 3: "Esparron" test site: 2D scatterplot of the Vegetation Index (VI) vs. the normalized brightness temperature. The wet/cold edge is in blue; the dry/warm edge is in red.



Figure 4: "Esparron" test site: map of the water index WI inferred from Fig. 3.
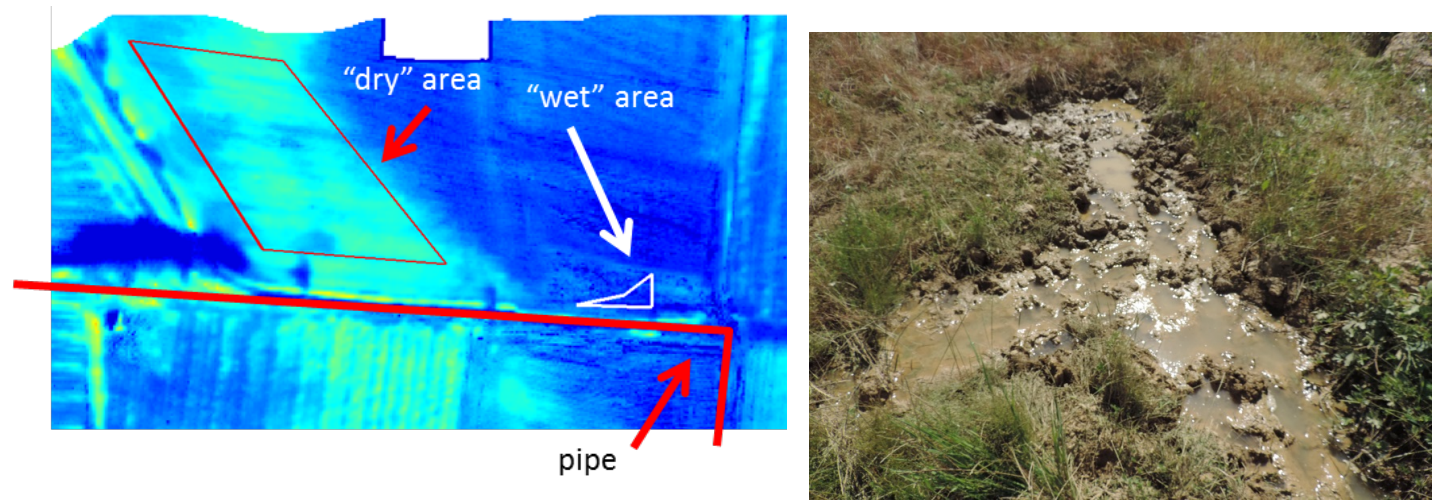

Figure 5: Left: close-up of the bottom part of the water index map in Fig. 4 showing the pipe location. The "wet" area corresponds to a puddle located just north to the pipe (see the picture at right). The "dry" area is an uphill well-drained field taken as reference. 
The "wet" area was chosen just north to the pipe where a puddle was detected amidst meadow (see Fig. 5-right). The triangular dark blue area corresponds to a depression extending downstream. The field just uphill on the left was covered with meadow as well and was chosen as a reference "dry" area. $\mathrm{C} / \mathrm{N}$ reached 5.6 in the TIR image and a very small value of 0.3 or 0.8 in the OSAVI, resp. NDVI image. After processing the triangle method we get a $\mathrm{C} / \mathrm{N}$ value of 6 or 6.1 when using OSAVI, resp. NDVI. We then infer that the main information about soil moisture is in the TIR image. Processing the T-VI scatterplot still improves slightly the result; however, using OSAVI or NDVI does not change significantly the final result.

We provide in Fig. 6 the image obtained when processing the index mNINSON [25] (mNINSON for minus NINSON since NINSON is anti-correlated with soil moisture). In Fig. 7 is the index n $|\mathrm{CAI}|$ index (i.e. the normalized absolute value of CAI index); CAI roughly represents the curvature of the reflectance spectrum between $2.0 \mu \mathrm{m}$ and $2.2 \mu \mathrm{m}$, which is of opposite sign for dry soils and stressed/senescent vegetation, whereas it is close to 0 for wet soils and well-watered vegetation [31].



Figure 6: Maps of the index mNINSON over the same area as in Fig. 5. High moisture is expected to be revealed by high values of mNINSON. A wavy horizontal line, not seen in Fig. 5, comes from an artifact in the SWIR images; it does not affect the $\mathrm{C} / \mathrm{N}$ computation in Fig. 8.

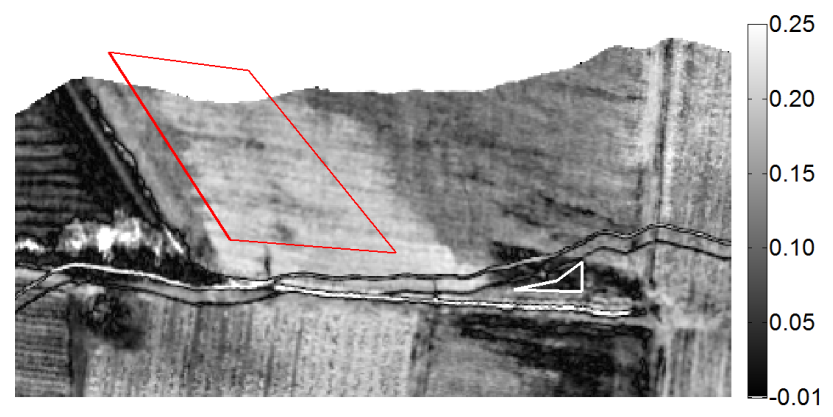

Figure 7: Maps of the index $n|C A I|$ over the same area as in Fig. 5. High moisture is expected to be revealed by values of $n|C A I|$ close to 0 . A double wavy horizontal line, not seen in Fig. 5, comes from an artifact in the SWIR images; it does not affect the C/N computation in Fig. 8. 




Figure 8: Contrast to noise ratio = contrast between "wet" and "dry" areas divided by the mean standard deviation of the signal (see Fig. 5-left). The information is extracted from index maps based on optical signals in the VNIR spectrum (orange bars), in the VNIR+SWIR spectra (green bars), in the SWIR spectrum alone (red bars), in TIR spectrum (blue bar), and in VNIR+TIR spectra (purple bars).

In Fig. 8 we can compare the $\mathrm{C} / \mathrm{N}$ obtained from a series of 22 images corresponding to a spectral signal (TIR), various indexes (reflectance ratios or normalized differences) claimed to give information on soil moisture, on water in vegetation, or simply on the vegetation state. Different colors have been displayed depending on the considered spectral regions.

Indexes obtained with VNIR signals alone provide very poor results: the contrast is lower than the mean variability in the two areas "dry" and "wet". The contrast seen in the PWI image is even of opposite sign of what is expected. One should combine VNIR with SWIR or use SWIR signals alone to get better results. For getting a $\mathrm{C} / \mathrm{N}$ higher than 3 one should use NSMI, NINSOL, NINSON, CAI or any of the four variants that we considered when applying the "optical trapezoid method" described in [32]. However, the best results (i.e. $\mathrm{C} / \mathrm{N}>5$ ) are obtained with $\mathrm{n}|\mathrm{CAI}|$ and with the thermal infrared data, let it be with the TIR signal alone or, slightly better, by combining it with NDVI or OSAVI through the triangle/trapezoid method.

The pipe in the Esparron area was finally checked for leaks with ultrasounds, but none was found. Hence, the water that was seen in the "wet" area should have a natural origin (groundwater exfiltration).

The same spectral analysis was performed over three areas containing artificial leaks. Figs. 9 and 10 are close-ups of the water index maps obtained in these areas by applying the T-VI Triangle/trapezoid method. In Le Tholonet (Fig. 9), a significant thermal contrast was observed over an area $13 \mathrm{~m} \times 31 \mathrm{~m}$ wide encompassing a buried pipe PEHD DN50 leaking through a $10 \mathrm{~mm}$ diameter hole and another control area (filled trench without pipe). The infrared camera has detected the water leak and the water spreading. On the opposite, no contrast was observed in the images obtained with the other indexes leveraging VNIR, SWIR or VNIR+SWIR signals alone.

About the same occurred in the Vauvenargues site where a pipe PEHD DN40 with four holes 5 or $10 \mathrm{~mm}$ diam., $15 \mathrm{~m}$ apart, was buried: all indices except the thermal-based one showed no contrast over the position of the leaking pipe. On the opposite, in the T-VI image (Fig. 10-left), a contrast could be detected, albeit quite faint. 


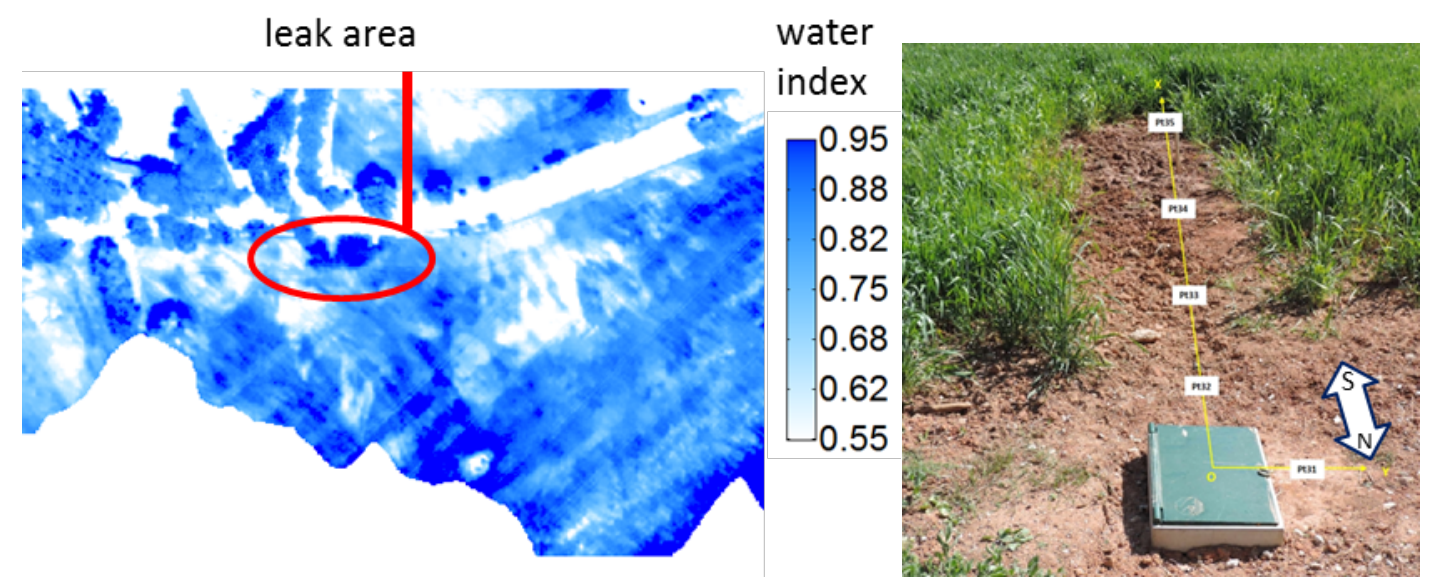

Figure 9: Water index map as obtained with the T-VI trapezoid method (OSAVI+TIR) over the Le Tholonet site. The area with an artificial leak is indicated in red. The left white indentation corresponds to a bare soil area containing a buried pipe with a $10 \mathrm{~mm}$ hole (see picture at right). The right indentation corresponds to a control area (bare soil) with no pipe. Water has diffused away from the leak spot (dark blue zone with high water index) and reached the control area.
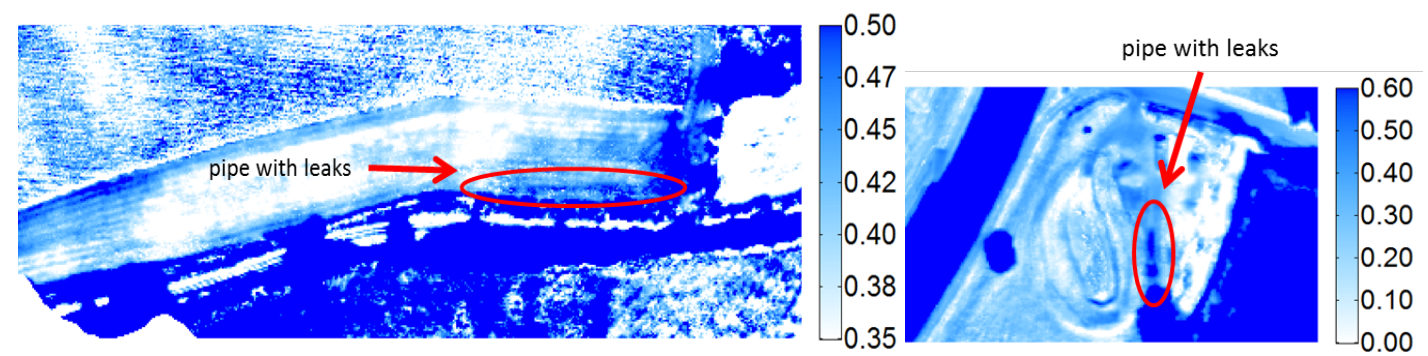

Figure 10: Same over the Vauvenargues site (left) and Rians site (right). In both cases, a pipe with artificial leaks has been connected to a water means and buried. The corresponding signature revealed by a higher water index (dark blue tone) is indicated with red ellipses.

In the Rians site, a pipe PEHD DN32 was buried with two holes $10 \mathrm{~mm}$ diam., $15 \mathrm{~m}$ apart. The thermal signature in the T-VI water index image was much clearer (see Fig. 10-right). A contrast could also be seen, albeit with a lower intensity, in the images obtained with the optical trapezoid method (OSAVI-SWIR or NDVI-SWIR [32]). Interestingly, the location of the buried pipe could also be seen in the mNINSOL, mNINSON, $\mid \mathrm{CAI}]$, and $\mathrm{n}|\mathrm{CAI}|$ images; however the contrast was of opposite sign to what was expected: this would be wrongly interpreted that the soil is drier than in the surroundings! One possible explanation could be that because the soil was recently worked, the optical properties of the surface in the SWIR spectrum had evolved and this change is more important than the one induced by a mere moisture change. 


\section{Conclusion}

An airborne remote sensing campaign was performed in rural environment over water transportation means for detecting leaks. Hyperspectral and thermal cameras were operated for getting spectral images encompassing VNIR, SWIR and TIR spectral bands. The best results were obtained by applying the triangle method fusing a thermal infrared image and a vegetation index image build upon two VNIR images. The contrast observed in the SWIR-based index images was lower and it sometimes showed an unexpected sign change. Further work will be devoted to establish a quantitative correlation between the water-index signature and the actual leak flow. Spectrally optimized optical sensors will be operated onboard a small plane and a UAV. In the future, the application of this approach could be considered in urban areas as well. Due to a large part of impervious surfaces (roads, pavements), their impact on the thermal manifestation of underground leaks should be specifically addressed.

\section{Acknowledgement}

This work has been supported by the EU-funded H2020 project WADI - Water-tightness Airborne Detection Implementation (www.waditech.eu) under Grant Agreement N 689239.

\section{References}

[1] V. I. Myer, Crops and soils. In Manual of Remote Sensing, American Society of Photogrammetry, Falls Church, Virginia, (1975) 1715-1813.

[2] M.D. Nellis, Application of thermal infrared imagery to canal leakage detection, Remote Sens. Environ., 12 (1982) 229-234.

[3] J.P. Tracey, P.A. Walton, Hydrologic investigations in canal and aqueduct systems using airborne thermal infrared linescanning, In Geoscience and Remote Sensing Symposium, IGARSS'89 12th Canadian Symposium on Remote Sensing, vol. 5, IEEE (1989) 2815-2819.

[4] J.M. Pickerill, T.J. Malthus, Leak detection from rural aqueducts using airborne remote sensing, Int. J. of Remote Sens. 19 (1998) 2427-2433.

[5] I.J. McGowen, S.L. Duff, I. Smith, Identifying channel seepage using pre-dawn thermal imagery, In Geoscience and Remote Sensing Symposium, IGARSS'01, 4, IEEE (2001) 1631-1633.

[6] Y. Huang, G. Fipps, S.J. Maas, R.S. Fletcher, Airborne remote sensing for detection of irrigation canal leakage, Irrig. and Drain., 59 (2009) 524-534.

[7] S.J. Thomson, , C. Ouellet-Plamondon, S.L. DeFauw, Y. Huang, D.K. Fisher, P.J. English, Potential and challenges in use of thermal imaging for humid region irrigation system management, J. Agric. Sci. 4, (2012) 103.

[8] M. Arshad, R. Gomez, A. Falconer, W. Roper, M. Summers, A remote sensing technique detecting and identifying water activity sites along irrigation canals, Am. J. Envir. Eng. \& Sci. 1 (2014) 19-35.

[9] S.L. Cundill, M. Meijde, R.G.K. Hack, Investigation of remote sensing for potential use of dike inspection, IEEE J. Sel. Top. Appl. Earth Obs. Rem. Sens., 7 (2014) 733-746.

[10] M.S. Moran, T.R. Clarke, Y. Inoue, A. Vidal, Estimating Crop water deficit using the relation between surface-air temperature and spectral vegetation index, Remote Sens. Environ. 49 (1994) 246-263. 
[11] T.N. Carlson, R.R. Gillies, T. G. Schmugge, An interpretation of methodologies for indirect measurement of soil water content, Agric. Forest Meteor. 77 (1995) 191-205.

[12] I. Sandholt, K. Rasmussen, J. Andersen, A simple interpretation of the surface temperaturevegetation index space for assessment of surface moisture status, Remote Sens. Environ. 79 (2002) 213-224.

[13] T.N. Carlson, An overview of the" triangle method" for estimating surface evapotranspiration and soil moisture from satellite imagery, Sensors, 7 (2007) 1612-1629.

[14] G. P. Petropoulos, G. Ireland, B. Barrett, Surface soil moisture retrievals from remote sensing: Current status, products \& future trends. Physics and Chemistry of the Earth, Parts $\mathrm{A} / \mathrm{B} / \mathrm{C}, 83$, (2015) 36-56.

[15] J.-C. Krapez, A. Olioso, B. Coudert, Comparison of three methods based on the temperatureNDVI diagram for soil moisture characterization, Proc. of SPIE 7472, 74720 (2009) 1-12.

[16] N.S. Chauhan, S. Miller, P. Ardanuy, Spaceborne soil moisture estimation at high resolution: a microwave-optical/IR synergistic approach, Int. J. Rem. Sens. 24 (2003), 4599-4622.

[17] J.-C. Krapez, A. Olioso, A combination of temperature, vegetation indexes and albedo, as obtained by airborne hyperspectral remote sensing, for the evaluation of soil moisture, J. Quant. Infr. Thermog., 8 (2011) 187-200.

[18] J.-C. Krapez, C. Chatelard, J.-F. Nouvel, P. Déliot, Combined airborne thermography and visible-to-near infrared reflectance measurement for soil moisture mapping, QIRT 2012 Conference, 11-14 June 2012, University of Naples Federico II, Naples, Italy.

[19] A. Maltese, C. Cammalleri, F. Capodici, G. Ciraolo, G. L. Loggia, Surface soil humidity retrieval using remote sensing techniques: a triangle method validation, Proc. of SPIE 7824, 782425, (2010) 1-8.

[20] A. Maltese, F. Capodici, G. Ciraolo, G. L. Loggia, Soil water content assessment: Critical issues concerning the operational application of the triangle method, Sensors, 15 (2015) 6699-6718.

[21] L. Fan, Q. Xiao, J. Wen, Q. Liu, Y. Tang, D. You, X. Li, Evaluation of the airborne CASI/TASI Ts-VI space method for estimating near-surface soil moisture, Remote Sensing, 7 (2015) 31143137.

[22] N. Sanchez, M. Piles, J. Martínez-Fernández, M. Vall-llossera, L. Pipia, A. Camps, C. M. Herrero-Jiménez, Hyperspectral optical, thermal, and microwave L-Band observations for soil moisture retrieval at very high spatial resolution, Photogram. Eng. \& Rem. Sens., 80 (2014) 745755.

[23] W.R. Whalley, P.B. Leeds-Harrison, G.E. Bowman, Estimation of soil moisture status using near infrared reflectance. Hydrol. Process. 5, (1991) 321-327.

[24] S.N. Haubrock, S. Chabrillat, C. Lemmnitz, H. Kaufmann, Surface soil moisture quantification models from reflectance data under field conditions. Int. J. Remote Sens. 29 (2008) 3-29.

[25] A. Lesaignoux, Estimation de l'humidité de surface des sols nus à partir de l'imagerie hyperspectrale à haute résolution spatiale sur le domaine optique 0.4-14 $\mu \mathrm{m}$, Thèse de l'Univ. de Toulouse, 16/12/2010.

[26] S. Fabre, X. Briottet, A. Lesaignoux, Estimation of soil moisture content from the spectral reflectance of bare soils in the 0.4-2.5 $\mu$ m domain. Sensors 15 (2015) 3262-3281.

[27] J. Peñuelas, J. Pinol, R. Ogaya, I. Filella, Estimation of plant water concentration by the reflectance water index WI (R900/R970). Int. J. of Remote Sens., 18 (1997) 2869-2875.

[28] P.J. Zarco-Tejada, C.A. Rueda, S.L. Ustin, Water content estimation in vegetation with MODIS reflectance data and model inversion methods. Remote Sens. Environ., 85 (2003) 109-124.

[29] B.C. Gao, NDWI-a normalized difference water index for remote sensing of vegetation liquid water from space, Remote Sens. Environ., 58 (1996) 257-266.

[30] D. Chen, J. Huang, T. J. Jackson, Vegetation water content estimation for corn and soybeans using spectral indices derived from MODIS near-and short-wave infrared bands, Remote Sens. Environ., 98 (2005) 225-236. 
[31] P. L. Nagler, C. S. T. Daughtry, S. N. Goward, Plant litter and soil reflectance, Remote Sens. Environ., 71 (2000) 207-215.

[32] M. Sadeghi, E. Babaeian, M. Tuller, S. B. Jones, The optical trapezoid model: A novel approach to remote sensing of soil moisture applied to Sentinel-2 and Landsat- 8 observations, Remote Sens. Environ., 198 (2017) 52-68.

[33] G. Brigot, E. Colin-Koeniguer, A. Plyer, F. Janez, Adaptation and evaluation of an optical flow method applied to coregistration of forest remote sensing images, IEEE J. Sel. Topics Appl. Earth Obs. Rem. Sensing, 9 (2016) 2923-2939.

[34] G. Rondeaux, M. Steven, F. Baret, Optimization of soil adjusted vegetation indices, Remote Sens. Environ., 55 (1996) 95-107. 